\title{
Inflammation and kidney involvement in human viral diseases caused by SARS-CoV-2, HIV, HCV and HBV
}

\author{
Gustavo Ferreira da Mata (1), Danilo Euclides Fernandes ${ }^{1}$ (1), Eduardo de Paiva Luciano ${ }^{1}$ (), \\ Gabriel Teixeira Montezuma Sales ${ }^{1}$ (D), Michelle Tiveron Passos Riguetti ${ }^{1}$ (D), Gianna Mastroianni Kirsztajn ${ }^{1 *}$ (D) \\ ${ }^{1}$ Department of Medicine (Nephrology), Federal University of São Paulo (Unifesp), São Paulo, SP, Brazil.
}

\section{Keywords: \\ COVID-19}

Glomerulonephritis

Hepatitis B

Hepatitis C

HIV

Inflammasome

SARS-COV-2

\begin{abstract}
Inflammation is closely related to renal diseases. This is particularly true for renal diseases caused by infections as in viral diseases. In this review, we highlight the inflammatory mechanisms that underlie kidney dysfunction in SARS-CoV-2, human immunodeficiency (HIV), hepatitis C (HCV), and hepatitis B (HBV) infections. The pathophysiology of renal involvement in COVID-19 is complex, but kidney damage is frequent, and the prognosis is worse when it happens. Virus-like particles were demonstrated mostly in renal tubular epithelial cells and podocytes, which suggest that SARS-CoV-2 directly affects the kidneys. SARS-CoV-2 uses the angiotensin-converting enzyme 2 receptor, which is found in endothelial cells, to infect the human host cells. Critical patients with SARS-CoV-2-associated acute kidney injury (AKI) show an increase in inflammatory cytokines (IL- $1 \beta$, IL-8, IFN- $\gamma$, TNF- $\alpha$ ), known as cytokine storm that favors renal dysfunction by causing intrarenal inflammation, increased vascular permeability, volume depletion, thromboembolic events in microvasculature and persistent local inflammation. Besides AKI, SARS-CoV-2 can also cause glomerular disease, as other viral infections such as in HIV, HBV and HCV. HIV-infected patients present chronic inflammation that can lead to a number of renal diseases. Proinflammatory cytokines and TNF-induced apoptosis are some of the underlying mechanisms that may explain the virus-induced renal diseases that are here reviewed.
\end{abstract}

* Correspondence: gm.kirsztajn@unifesp.br https://doi.org/10.1590/1678-9199-JVATITD-2020-0154 


\section{Background}

Renal diseases and inflammation are closely linked. This is particularly true for renal diseases caused by infections as in viral diseases. For example, the terms "glomerulonephritis" and "tubulointerstitial nephritis" themselves contain a suffix that means inflammation (from the Greek, 'itis').

In renal diseases, inflammation can be seen as complex interactions between renal parenchymal and resident immune cells (macrophages and dendritic cells) in association with the recruitment of circulating cells (monocytes, lymphocytes, and neutrophils), which stimulate receptors (Toll-like receptor and Nod-like receptor) that initiate major innate immunity pathways. One of them - the NLRP3 (or NACHT, LRR, and PYD domaincontaining protein 3) inflammasome - induces inflammatory mediators secretion that ends in irreversible tissue damage and functional loss [1].

The podocytes, resident visceral epithelial cells that constitute the glomerulus, can express all the inflammasome components of NLRP3 that seems to be involved in the inflammatory mechanisms that underlies acute kidney injury (AKI) and chronic kidney disease (CKD) [2,3].

Regardless of the cause of CKD, fibrosis represents a common final pathway that leads to end-stage kidney disease (ESKD). Inflammation is involved in this process and transforming growth factor- $\beta$ (TGF- $\beta$ ), which plays a potent anti-inflammatory effect by regulating negatively the renal inflammation, is an important mediator of renal fibrosis [4].
The NLRP3 inflammasome plays different roles in the pathogenesis of renal fibrosis as it mediates the inflammatory response and it also promotes pyroptosis, mitochondrial regulation, and myofibroblast differentiation [3]. NLRP3 activation in renal diseases aggravates inflammation, as well as the consequent fibrosis.

It is now known that NLRP3 has several inflammasomedependent and independent functions in the kidney. The inflammasome-dependent NLRP3 mediates the progression of kidney diseases by escalating local kidney inflammatory response and promoting a crosstalk between the immune cells and the nonimmune renal cells. On the other hand, the inflammasomeindependent NLRP3 regulates tubular epithelial cells apoptosis [3].

In this review, we discuss evidence on inflammatory processes that underlie some of the most frequent viral-induced kidney diseases - SARS-CoV-2, human immunodeficiency (HIV), hepatitis $\mathrm{B}(\mathrm{HBV})$, and $\mathrm{C}(\mathrm{HCV})$ viruses.

\section{Methods}

We used different strategies to search the subjects we present in this article, which included the PubMed/Medline database. We pre-selected four major topics based on their current relevance worldwide - infections due to SARS-CoV-2, HIV, HBV and HCV. The search strategy we used in PubMed was based on the terms described in Figure 1 that shows the article selection flow chart. We also included some relevant manuscripts that could enrich this review.

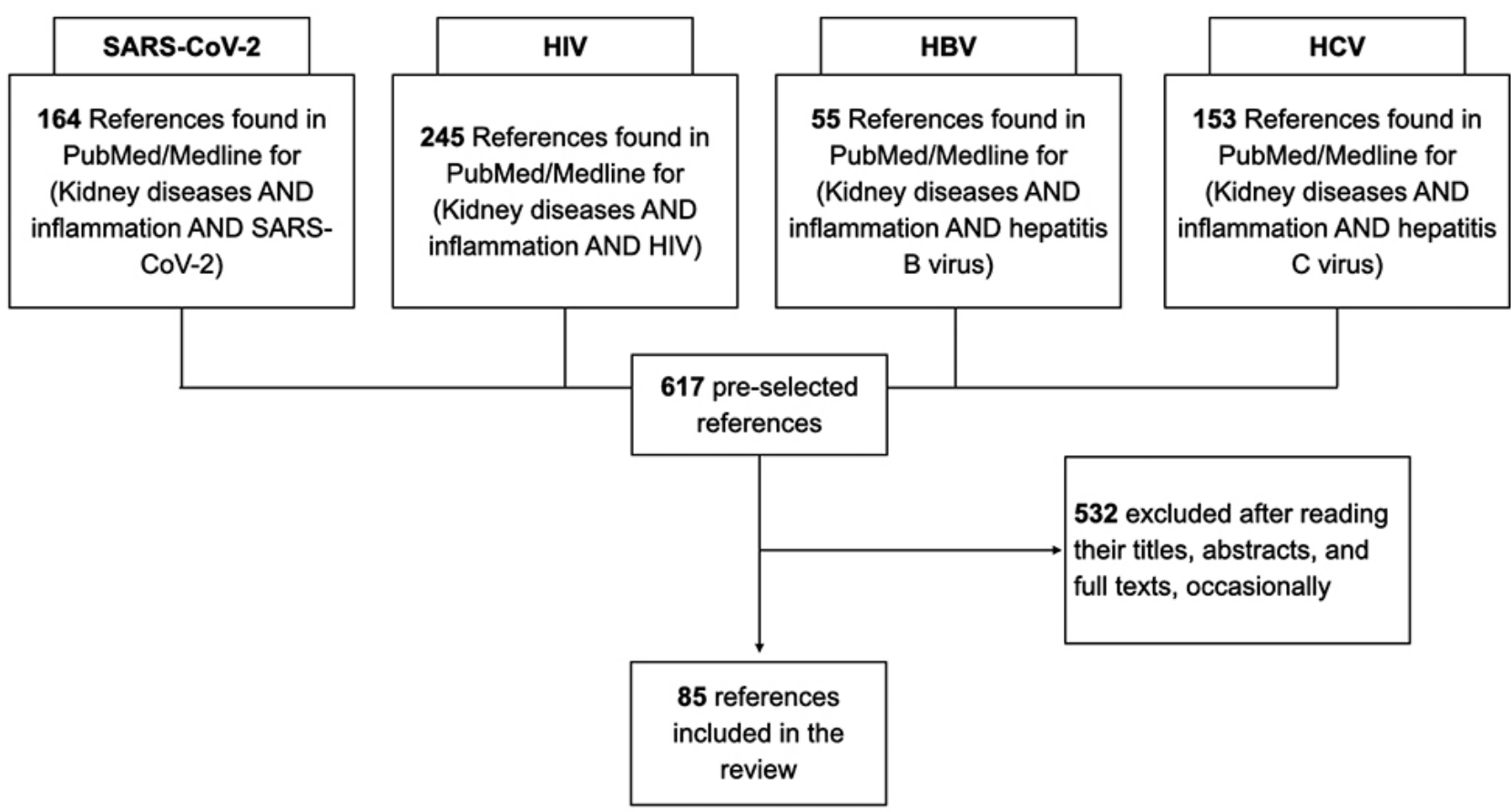

Figure 1. Article selection flow chart. HIV: human immune deficiency virus; HBV: hepatitis B virus; HCV: hepatitis $C$ virus. 


\section{SARS-CoV-2}

In December 2019, a group of patients with pneumonia of an unknown cause was observed in Wuhan, China [5]. On December 31, 2019, the Chinese Center for Disease Control and Prevention conducted epidemiologic and etiologic investigations and, then, the Chinese authorities reported to the World Health Organization (WHO) about such disease [5,6]. Chinese scientists identified a new viral agent - the novel coronavirus, at that time - on January 7, 2020. Few weeks later, on January 30, 2020, the WHO declared a "public health emergency of international concern" [6]. On February 11, 2020, the WHO officially named the disease as the novel coronavirus disease 2019 (COVID-19) and the Coronavirus Study Group (CSG) of the International Committee proposed to name the new coronavirus as SARSCoV-2 [7].

Human coronaviruses are enveloped single-stranded RNA viruses, order Nidovirales. Seven different serotypes of coronaviruses cause human diseases, some of which lead to mild upper respiratory symptoms, but others may be fatal. SARS$\mathrm{CoV}-2$ is a betacoronavirus lineage $\mathrm{B}$ known to cause a severe respiratory disease that can affect other organs and tissues [8]. The COVID-19 raises at an overwhelming rate, reaching more than 32 million cases and more than 980,000 deaths worldwide [9]. In Brazil, there is more than 4,6 million cases and more than 139.000 deaths by September 2020 [9] and these numbers are still increasing.

To date, the COVID-19 does not has predilection for ethnicity and most patients (87\%) were between 30 and 79 years old in China [6]. Recently, Kawasaki-like disease was reported in children, but further studies should confirm its association with the SARS-COV-2 infection [10]. Some factors seem to favor a more severe disease: hypertension, diabetes, obesity, aging, immunosuppression, among others [11].

The COVID-19 presents with a wide spectrum of clinical manifestations, from asymptomatic and oligosymptomatic to critical illness that requires intensive care and mechanical ventilation. The COVID-19 can evolve in three patterns: mild disease (80-85\% of all cases) with fever, cough, sore throat, fatigue, malaise, headache, myalgia, and no evidence of pneumonia. In general, these symptoms are self-limited with no necessity of hospitalization or medical interventions. Despite the mild symptoms, the viral load can be high. The second pattern (10$15 \%$ of all cases) corresponds to a moderate-to-severe disease or a biphasic disease in which lungs are involved (pneumonia) besides the mild symptoms that can last for two weeks. The third pattern corresponds to the critical patients who present with shock, sepsis, severe hypoxemia, multiple organ failure, necessity of mechanical ventilation, and intensive care. About $5 \%$ of all cases may have this course, which symptoms can last for three weeks. Such critical cases initiate with high viral load followed by immune system overactivation when the viral load decreases [12]. Even though the COVID-19 is a respiratory disease, there is systemic involvement that commonly affects skin, intestinal tract, kidney, blood vessels, brain, and heart [13-17].
Laboratory findings reflect the changes in inflammatory biomarkers (C-reactive protein, interleukin [IL]-6, erythrocyte sedimentation rate, lactic dehydrogenase), coagulation disorders (thrombocytopenia and increased d-dimer), and lymphopenia, none of which are COVID-19 specific [14].

Renal involvement in the COVID-19 remains diverse and frequent, suggests a severe course and predicts a poor survival rate $[18,19]$. The renal disorders may present with hematuria and proteinuria (asymptomatic urinary abnormalities), collapsing glomerulopathy, acute diffuse glomerulonephritis, AKI (e.g. acute tubulointerstitial nephritis), endothelial injury and renal microvessel thrombosis [20-24].

The prevalence of AKI in patients varies from 3.0 to $30 \%$ $[20,21,25,26]$, but it was also shown that the rate of AKI was $89.7 \%$ among the patients who needed mechanical ventilation compared with $21.7 \%$ among the other patients who did not need intensive care [27].

The kidneys receive a large amount of blood and they have a huge vascular network with a highly active endothelium. The SARS-CoV-2 gains access to the kidney through the bloodstream, as approximately $15 \%$ of the patients were found to have RNAemia [28]. Therefore, it becomes an active target for countless cytokines, complement system, and inflammatory processes. In addition, the kidneys express the angiotensinconverting enzyme 2 (ACE2) in large quantities, which SARS$\mathrm{CoV}-2$ uses to enter the host cells. ACE2 is mostly expressed on the apical brush-border membrane of the proximal tubule cells, but it is also present in podocytes at lower levels [29].

The critical patients that present with SARS-CoV-2- associated AKI show an increase in inflammatory cytokines such as IL$1 \beta$, IL- 8, IFN- $\gamma$, TNF- $\alpha$, when compared to the non-critical patients [8]. Besides the viral cytotoxic effect and the cytokines storm, a favorable environment for renal dysfunction includes intrarenal inflammation, increased vascular permeability, volume depletion, thromboembolic events in microvasculature and a persistent localized inflammatory process [8].

The pathophysiology of renal impairment in the COVID-19 is complex [27]. Some authors demonstrated that SARS-CoV-2 could directly infect human kidney tubules and induce cytoplasmic renal tubular inclusions $[22,30]$. They also found C5b-9 in renal tubular cells that may indicate complement system activation in SARS-CoV-2 infection [26]. An interaction among angiotensin II (AngII) overactivity, innate/adaptive immune response, and complement and coagulation systems could influence AKI severity and its outcomes. Inflammation-induced erythrocyte aggregation and heme-mediated injury may increase oxidative stress, inflammation, and complement activation, which may promote microvascular injury [29].

In addition to the inflammatory/immune-mediated mechanisms the SARS-CoV-2-associated AKI may be ascribed to different causes such as impaired gas exchange, hemodynamic alterations including right heart failure, fluid overload, and systemic congestion, injurious mechanic ventilation strategies, and secondary infections/sepsis [20]. 
In general, viral infections can cause many kidney diseases, which diagnosis depend on clinical and laboratory investigations, as well as histological analysis. Many mechanisms are involved, including viral kidney tropism, induction of abnormal immune complexes, direct cytopathic effects, and multiorgan failure [31]. SARS-CoV-2 infection can trigger glomerular diseases (several types were reported, including collapsing glomerulopathy) or aggravate a pre-existing disease $[23,32]$.

Besides tubular or glomerular disorders, there is endothelial dysfunction and microvascular injury [33]. Post mortem analyses indicate that kidney and lung endothelium are affected, which may be responsible for proteinuria [19] and prothrombotic state [33]. As previously mentioned, SARS-CoV-2 uses the ACE2, which is expressed by the endothelial cells, to infect the host cells [34]. There is evidence of direct viral infection of such cells and diffuse endothelial inflammation. The endothelial involvement could explain the variety of clinical manifestations in different organs and systems. Despite the progress towards COVID-19 understanding, further studies will clarify the underlying mechanisms through which SARS-CoV-2 affects the kidneys and, then, more effective approaches may be suggested.

\section{HIV}

Human immunodeficiency virus (HIV) is an RNA virus. Since the first reports in the 1980s, natural history of HIV infection has changed drastically due to the advent of antiretroviral therapy (ART). Currently, the life expectancy of HIV-infected individuals who are under ART matches the life expectancy of those who are HIV-uninfected [35].

A pro-inflammatory state was described since the beginning of the HIV pandemic, which includes higher serum levels of IL-6, TNF- $\alpha$, TGF- $\beta$, and other inflammatory molecules [36]. Additionally to the immune system aging (known as "inflammaging”), those who live with HIV becomes more vulnerable to a chronic inflammatory state that can lead to some diseases [37], including renal dysfunction.

With regards to kidneys, we can schematically divide those disorders into four main groups, all of which can cause CKD or ESKD: (1) AKI; (2) HIV-associated kidney disease; (3) associations with other risk factors for CKD; and (4) treatmentrelated toxicity [38].

AKI remains very common among HIV-infected individuals and accounts for the increase in the incidence of renal replacement therapy [38-40]. Besides age-related diseases such as diabetes, hypertension, $\mathrm{CKD}$, and liver diseases, sepsis still is the pivotal risk factor for AKI [38,40,41].

Three major scenarios are more likely in HIV-associated kidney disease: HIV-associated nephropathy (HIVAN), HIV-associated immune complex kidney disease (HIVICK), and thrombotic microangiopathy. HIVAN usually happens in the late stages of HIV infection with or without acquired immunodeficiency syndrome (AIDS). Some APOL1 polymorphisms may suggest a higher risk for HIVAN $[38,42]$. Management of HIVICK remains unclear [38], as the pathophysiology of thrombotic microangiopathy in HIV [43], but some studies have shown that HIV is highly associated with thrombotic thrombocytopenic purpura [44-46] or, less frequently, hemolytic uremic syndrome [47].

The associations between HIV infection and CKD itself or its risk factors include both modifiable factors (diabetes, hypertension, and hepatitis B and C) and non-modifiable ones (ethnicity) $[38,48,49]$. Although $5.8 \%$ of acute HIV-infected subjects may present proteinuria, the prevalence of estimated glomerular filtration rate $(\mathrm{eGFR})<60 \mathrm{~mL} / \mathrm{min}$ tends to be even lower $(0.5 \%)$ among those individuals [38,50-52]. Over the past decades and in light of modern antiretroviral regimens, focal segmental glomerulosclerosis, diabetic nephropathy, arteriolar nephrosclerosis (with or without hypertension), immune complexes diseases (with or without liver disease), and toxicity replaced the previous most frequent histopathological finding, the collapsing glomerulopathy [38].

Treatment-related toxicity usually happens after long-term exposure to nephrotoxic antiretrovirals such as tenofovir (TFV), which is frequently used for treating and preventing (pre- and post-exposure prophylaxis) HIV infection. Other antiretrovirals have been associated with nephrotoxic events as indinavir, ritonavir, atazanavir, and lopinavir, but only TFV nephrotoxicity is well-described. TFV commonly causes isolated proximal tubular dysfunction by intoxicating the mitochondria within the tubular epithelial cells, which can lead them to apoptosis. Laboratory findings can show low molecular weight proteinuria, mild albuminuria, a decrease in eGFR, and Fanconi syndrome. The main risk factors for such effects are eGFR < $60 \mathrm{~mL} / \mathrm{min}$ and ART with TFV boosters (protease inhibitors, such as atazanavir and ritonavir) that plays an important combination for treating $\mathrm{HIV}$-infection. TFV-nephrotoxicity can be reverted after interrupting its use, although some reports suggest irreversibility $[38,53]$.

\section{HBV}

HBV infection is of global public health concern. In 2015, the WHO estimated 257 million HBV-infected individuals around the world and approximately 887,000 people died from $\mathrm{HBV}$ related liver disease by that year [54]. Nearly 250 to 350 million people (5\% of the world's population) are chronically $\mathrm{HBV}$ infected, which makes $\mathrm{HBV}$ to be one of the most common human pathogens. Additionally, 3\% to $5 \%$ of the patients with chronic $\mathrm{HBV}$ infection may develop kidney disease as a complication [55].

The HBV-associated renal diseases frequently occur during the childhood in endemic areas, which likely turn the patient into a chronic carrier [56]. Children with HBV-related membranous nephropathy $(\mathrm{MN})$ have a high spontaneous remission rate and rarely progress to ESKD. Otherwise, adults with HBV-related MN show higher progression risk [55].

Among the glomerular diseases most associated with HBV infection are $\mathrm{MN}$, membranoproliferative glomerulonephritis (MPGN), IgA nephropathy (IgAN), cryoglobulinemia, and polyarteritis nodosa (PAN; Kussmaul-Meier disease). About 10\% 
of the HBV-infected subjects are coinfected with HIV and 10$30 \%$ are coinfected with HCV. As coinfection with HIV and $\mathrm{HCV}$ is quite common, those at higher risk (e.g., intravenous drug use, unprotected sex) should also be screened for these viruses [57]. Another reason for screening the patients with proteinuric glomerular diseases for $\mathrm{HBV}$ infection is that immunosuppressive therapy can exacerbate HBV replication.

The diagnosis of HBV-related glomerulonephritis requires a meticulous laboratory investigation, which includes serum biomarkers levels, detection of viral particles in blood sample, and detection of HBV antigens in kidney histopathological study. Furthermore, any other causes of glomerular disease must be ruled out. HBV infection can be silent and can show no sign of liver damage - as increased hepatic enzymes -, thus a liver biopsy can clarify the level of organ injury [58].

$\mathrm{HBV}$-associated secondary $\mathrm{MN}$, as other forms of $\mathrm{MN}$, usually presents with proteinuria, which can reach a nephrotic range. Compared with the patients who have primary MN, those with $\mathrm{HBV}$-associated $\mathrm{MN}$ are more likely to have microscopic hematuria and lower complement levels. At the histopathological study, the presence of mesangial or subendothelial immune deposits associated with its typical subepithelial localization may suggest secondary rather than primary $\mathrm{MN}$ [59]. It was shown a low prevalence of anti-phospholipase A2 receptor (PLA2R) antibodies and/or PLA2R staining of the immune deposits in $\mathrm{HBV}$-associated MN [60,61].

$\mathrm{HBV}$-associated MPGN, as other forms of MPGN, presents with hematuria, variable degrees of proteinuria, reduced GFR, and hypertension. The deposition of circulating antigen-antibody complexes in the mesangium and subendothelial space is observed in HBV-associated MPGN. Both HBsAg and HBeAg deposition have been implicated in this disorder, although their exact role remains uncertain. Compared to $\mathrm{HCV}, \mathrm{HBV}$ infection is a rare cause of mixed cryoglobulinemia, which can be associated with MPGN [62].

PAN is a necrotizing vasculitis that affects both smalland medium-sized blood vessels, which involves multiple organs frequently. The PAN-related renal involvement leads to variable degrees of reduced glomerular filtration ratio (GFR) and hypertension. The clinical features of HBV-associated PAN are similar to the idiopathic one. HBV-associated PAN typically occurs within four months after the onset of HBV infection. The vessel wall deposits of circulating antigen-antibody immune complexes triggers the following inflammatory processes [56].

As concerned to other underlying mechanisms of $\mathrm{HBV}$-related renal diseases, the presence of HBV-DNA and RNA in renal tubular epithelial cells (RTECs) suggests direct virus-induced injury. Increased proinflammatory cytokines are also observed under those conditions. Apoptosis, which is mostly induced by the TNF-related apoptosis-inducing ligand (TRAIL), plays a significant role in the pathogenesis of HBV-infections. However, the effects of HBV X protein (HBx) on TRAIL-induced apoptosis of RTECs, especially under certain inflammatory conditions remain unclear. HBx synergizes with proinflammatory cytokines to significantly increase TRAIL-induced apoptosis of RTECs.
HBx markedly upregulates the death receptor-4 (DR4) expression by enhancing the activation of nuclear factor-kappa B when proinflammatory cytokines are present. A dramatic increase in DR4 expression leads to the sensitization of RTECs to TRAILinduced apoptosis. Furthermore, in those with HBV-associated glomerulonephritis, DR4 expression in the kidneys is significantly elevated and it correlates positively with $\mathrm{HBx}$ and proinflammatory cytokines expression. Such findings provide a novel insight into the underlying mechanisms of renal tubule lesions induced by $\mathrm{HBx}$ in HBV-associated glomerulonephritis [63].

Notch1 plays an important part in regulating immune responses and epithelial-mesenchymal transdifferentiation (EMT). It was previously observed inflammatory cell infiltration and tubulointerstitial fibrosis in the renal biopsies from the patients with $\mathrm{HBV}$-associated glomerulonephritis. It has been suggested that Notch1 is significantly associated with renal tubular and interstitial lesions. Notch1 can mediate HBx-induced EMT of human proximal tubular epithelial cells (HK-2), promote $\mathrm{HBx}$-induced increases in immune molecule expression and exacerbation of cytokine disorders, which may contribute to the progression of $\mathrm{HBV}$-associated glomerulonephritis. Inhibitors of Notch1 signaling may be useful as new therapeutic strategy at HBV-associated glomerulonephritis [64].

\section{HCV}

$\mathrm{HCV}$ is an RNA virus from the Flaviviridae family which was first described in 1989. Prior to the HCV description, many cases of chronic hepatitis among individuals who underwent blood transfusion history were called non-A, non-B hepatitis, since no etiology could be identified, as well as most cases of cryoglobulinemia were considered idiopathic [65]. Nowadays, $\mathrm{HCV}$ is an endemic infection worldwide, with more than 170 million people infected that can complicate with cirrhosis, hepatocellular carcinoma and cryoglobulinemia [66]. Recently, the direct-acting antivirals revolutionized the treatment of $\mathrm{HCV}$ as the sustained viral response jumped from close to $50 \%$ to over $90 \%$ [67]. Even more striking improvement is found among poor responders, which usually include $\mathrm{CKD}$ and cirrhotic patients [68]. These results are the motivation to 2030 WHO's goal to reduce the incidence of $\mathrm{HCV}$ in $80 \%$ and mortality in 65\% [69].

HCV has mainly hepatocytes tropism but it can also infect lymphocytes, which may explain the extrahepatic manifestations, as some cohorts show a prevalence close to $70 \%$ in chronic infected patients, including porphyria cutanea tarda, insulin resistance, thyroiditis, lymphoma and systemic vasculitis $[70,71]$. Clinical manifestations related to the kidneys are commonly seen, as hematuria, proteinuria, AKI, edema and hypertension, because of which annual screening with eGFR and urinalysis is recommended in HCV-infected patients [72]. Mcguire et al. have demonstrated through protocol kidney biopsies during liver transplantation that up to $85 \%$ of chronic infected patients present any kidney involvement that can be attributed to HCV [73]. Immune complex-mediated MPGN associated to cryoglobulinemia remains the most common 
renal disease, usually manifested as a systemic vasculitis purpura, arthralgia, peripheric neuropathy and nephropathy characterized by subendothelial deposits of immune-complexes containing immunoglobulin $\mathrm{M}(\operatorname{IgM})$ autoantibodies against the Fc fragment of immunoglobulin $\mathrm{G}(\mathrm{IgG})$ that precipitate in cold, called cryoglobulins [74].

Cryoglobulinemia is classified in three types according to autoantibodies clonality. Type 1 is associated with lymphoproliferative diseases and both $\operatorname{IgG}$ and $\operatorname{IgM}$ are monoclonal. Type 2, or mixed cryoglobulinemia, has monoclonal IgM and polyclonal IgG, while type 3 is completely polyclonal. The last two are associated with autoimmune diseases, and especially with HCV chronic infections, with a prevalence of around $90 \%$ among those with mixed cryoglobulinemia, including evidence of viral-containing immune complexes $[74,75]$. This phenomenon can be explained by the HCV ability to infect $\mathrm{B}$ lymphocytes through the $\mathrm{CD} 81$ glycoprotein, as well as by the mimicry of HCV-specific proteins, as NS3, which is similar to the IgG-Fc component, stimulating autoantibodies production $[73,76]$. Besides that, an impairment in phagocyte system activity has been correlated with a higher renal exposition to cryoglobulins, which can explain why up to $50 \%$ of the HCV-infected patients present serum cryoglobulins but only around $5 \%$ of them develop active inflammatory disease [77,78]. Another mechanism involved in the HCV-related immunological dysregulation is increased levels of B lymphocyte stimulator, a cytokine related to $B$ cell proliferation and survival $[79,80]$.

Kidney histology in cryoglobulinemia is usually characterized by endocapillary and mesangial proliferation, with a classical double-contoured appearance, a pattern known as MPGN. Sometimes hyaline intracapillary thrombi, microtubular structures and fibrillar deposits can also be observed by electron microscopy [75]. Other kidney disorders less frequently associated with $\mathrm{HCV}$ are immune-complex-related glomerular diseases as MPGN without cryoglobulinemia, $\mathrm{MN}$ and fibrillary glomerulopathy. Mesangial proliferative glomerulonephritis, tubulointerstitial nephritis, PAN and focal segmental glomerulosclerosis can also be found and for the last two a direct virus-induced damage to podocytes and tubular cells hypothesis has been defended $[68,67]$.

Despite the limitations of the immunosuppressive therapy and considering that the main goal is to reach a sustained viral response, it is recommended to perform kidney biopsy when there is clinical suspicion of glomerulopathies - proteinuria or progressive kidney failure associated with hematuria [72].

As already mentioned, the treatment of $\mathrm{HCV}$-associated nephropathy invariably needs antiviral therapies. Some cases that present with a more severe kidney involvement, such as nephrotic syndrome or AKI, should also be treated with immunosuppressive agents. Rituximab or cyclophosphamide plus corticosteroids remain the most common associations. Those who present with a life-threatening condition may benefit from therapeutic plasma exchange [81]. Since 2014, when direct acting antivirals were first described - NS3/4A, NS5A and NS5B inhibitors - the treatment of HCV has turned highly effective, and some combinations can reach $100 \%$ of sustained viral response. Unfortunately, although these new drugs can eliminate $\mathrm{HCV}$, immune manifestations such as glomerulonephritis may still remain with an unsatisfactory remission rate, which emphasizes the need for considering immunosuppressive therapy in critical cases [68]. An HCVinduced immunological trigger may be responsible for a poor response to the treatment because $\mathrm{HCV}$ can infect $\mathrm{B}$ lymphocytes in a partially irreversible way, which may explain why many patients benefit from the immunosuppressive therapy [67].

\section{Conclusion}

Inflammation participates in the pathogenesis of renal diseases, with a relevant role in such affections associated with infections. Moreover, it influences progression to ESKD.

In 2020, the outbreak of a new viral disease, the COVID-19, drew attention to the inflammatory mechanisms that underlies this and other viral infections. In COVID-19, inflammation was associated with a myriad of clinical manifestations, and severe renal involvement. The unique features of SARS-CoV-2 related to renal diseases and their inflammatory mechanisms were described in the present study, as those of the HIV, HCV and HBV infections.

\section{Abbreviations}

ACE2: angiotensin-converting enzyme 2; AIDS: acquired immunodeficiency syndrome; AKI: acute kidney injury; AngII: angiotensin II; APOL1: apoliprotein 1; ART: antiretroviral therapy; CKD: chronic kidney disease; COVID-19: coronavirus disease 2019; DR4: death receptor-4; eGFR: estimated glomerular filtration rate; EMT: epithelial-mesenchymal transdifferentiation; ESKD: end-stage kidney disease; GFR: glomerular filtration rate; HBsAg: hepatitis $B$ surface antigen; HBV: hepatitis $B$ virus; HCV: hepatitis $C$ virus; HIV: human immunodeficiency virus; HIVAN: HIV-associated nephropathy; HIVICK: HIV-associated immune complex kidney disease; IgAN: IgA nephropathy; IgG: immunoglobulin G; IgM: immunoglobulin M; IL: interleukin; INF: interferon; MN: membranous nephropathy; MPGN: membranoproliferative glomerulonephritis; NLRP3: NACHT, LRR, and PYD domain-containing protein 3; PAN: polyarteritis nodosa; PLA2R: phospholipase A2 receptor; RTECs: renal tubular epithelial cells; SARS-CoV-2: severe acute respiratory syndrome coronavirus 2; TFV: tenofovir; TGF: transforming growth factor; TNF: tumor necrosis factor; TRAIL: TNF-related apoptosis-inducing ligand; WHO: World Health Organization.

\section{Availability of data and materials}

Not applicable.

\section{Funding}

This research group was supported by the Coordination for the Improvement of Higher Education Personnel (CAPES - 
finance code 001) and the National Council for Scientific and Technological Development (CNPq - grants to GFM and GMK).

\section{Competing interests}

The authors declare that they have no competing interests.

\section{Authors' contributions}

GMK conceptualized the article. All authors wrote the text, reviewed and approved the final manuscript.

\section{Ethics approval}

Not applicable.

\section{Consent for publication}

Not applicable.

\section{References}

1. Andrade-Oliveira V, Foresto-Neto O, Watanabe IKM, Zatz R, Câmara NOS. Inflammation in renal diseases: new and old players. Front Pharmacol. 2019 Oct 8;10:1192.

2. Xiong W, Meng X-F, Zhang C. Inflammasome activation in podocytes: a new mechanism of glomerular diseases. Inflamm Res. 2020 Aug;69(8):731-743.

3. Chi K, Geng X, Liu C, Cai G, Hong Q. Research progress on the role of inflammasomes in kidney disease. Mediators Inflamm. 2020 Jan 29;2020:1-9.

4. Gu Y-Y, Liu X-S, Huang X-R, Yu X-Q, Lan H-Y. Diverse role of TGF- $\beta$ in kidney disease. Front Cell Dev Biol. 2020 Feb 28;8:123.

5. Zhu N, Zhang D, Wang W, Li X, Yang B, Song J, et al. A novel Coronavirus from patients with pneumonia in China, 2019. N Engl J Med. 2020 Feb 20;382(8):727-733.

6. Wu Z, McGoogan JM. Characteristics of and important lessons from the Coronavirus disease 2019 (COVID-19) outbreak in China: summary of a report of 72314 cases from the Chinese Center for disease control and prevention. JAMA. 2020 Apr 7;323(13):1239-1242.

7. Guo Y-R, Cao Q-D, Hong Z-S, Tan Y-Y, Chen S-D, Jin H-J, et al. The origin, transmission and clinical therapies on coronavirus disease 2019 (COVID-19) outbreak - an update on the status. Mil Med Res. 2020 Mar 13;7(1):11.

8. Martinez-Rojas MA, Vega-Vega O, Bobadilla NA. Is the kidney a target of SARS-CoV-2? Am J Physiol Renal Physiol. 2020 Jun 1;318(6):F1454-F1462.

9. Center CR. Johns Hopkins University Medicine [Internet]. Johns Hopkins University Medicine; 2021 [cited 2021 Feb 25]. COVID-19 Dashboard by the Center for Systems Science and Engineering (CSSE) at Johns Hopkins University (JHU); [about 1p]. Available from: https://coronavirus. jhu.edu/map.html

10. Viner RM, Whittaker E. Kawasaki-like disease: emerging complication during the COVID-19 pandemic. Lancet. 2020 Jun 6;395(10239):1741-1743.

11. Guan W-J, Ni Z-Y, Hu Y, Liang W-H, Ou C-Q, He J-X, et al. Clinical characteristics of Coronavirus disease 2019 in China. N Engl J Med. 2020 Apr 30;382(18):1708-1720.

12. Lescure F-X, Bouadma L, Nguyen D, Parisey M, Wicky P-H, Behillil S, et al. Clinical and virological data of the first cases of COVID-19 in Europe: a case series. Lancet Infect Dis. 2020 Jun;20(6):697-706.

13. Ge H, Wang X, Yuan X, Xiao G, Wang C, Deng T, et al. The epidemiology and clinical information about COVID-19. Eur J Clin Microbiol Infect Dis. 2020 Jun;39(6):1011-1019.

14. Rodriguez-Morales AJ, Cardona-Ospina JA, Gutiérrez-Ocampo E, Villamizar-Peña R, Holguin-Rivera Y, Escalera-Antezana JP, et al. Clinical, laboratory and imaging features of COVID-19: a systematic review and meta-analysis. Travel Med Infect Dis. 2020 Mar-Apr;34:101623.
15. Spinato G, Fabbris C, Polesel J, Cazzador D, Borsetto D, Hopkins C, et al. Alterations in smell or taste in mildly symptomatic outpatients with SARS-CoV-2 infection. JAMA. 2020 May 26;323(20):2089-2090.

16. European Centre for Disease Prevention and Control. Novel coronavirus disease 2019 (COVID-19) pandemic: increased transmission in the EU/ EEA and the UK - sixth update - 12 March 2020. Stockholm; 2020.

17. Berlin DA, Gulick RM, Martinez FJ. Severe Covid-19. N Engl J Med. 2020 Dec 17;383(25):2460.

18. Rovin BH, Caster DJ, Cattran DC, Gibson KL, Hogan JJ, Moeller MJ, et al. Management and treatment of glomerular diseases (part 2): conclusions from a kidney disease: improving global outcomes (KDIGO) controversies conference. Kidney Int. 2019 Feb;95(2):281-295.

19. Ronco $C$, Reis T, Husain-Syed F. Management of acute kidney injury in patients with COVID-19. Lancet Respir Med. 2020 Jul;8(7):738-742.

20. Fanelli V, Fiorentino M, Cantaluppi V, Gesualdo L, Stallone G, Ronco C, et al. Acute kidney injury in SARS-CoV-2 infected patients. Crit Care. 2020 Apr 16;24(1):155.

21. Naicker S, Yang C-W, Hwang S-J, Liu B-C, Chen J-H, Jha V. The novel Coronavirus 2019 epidemic and kidneys. Kidney Int. 2020 May;97(5):824-828.

22. Farkash EA, Wilson AM, Jentzen JM. Ultrastructural evidence for direct renal infection with SARS-CoV-2. J Am Soc Nephrol. 2020 Aug;31(8):1683-1687.

23. Larsen CP, Bourne TD, Wilson JD, Saqqa O, Sharshir MA. Collapsing glomerulopathy in a patient with COVID-19. Kidney Int Rep. 2020 Apr 9;5(6):935-939.

24. Cheng Y, Luo R, Wang K, Zhang M, Wang Z, Dong L, et al. Kidney disease is associated with in-hospital death of patients with COVID-19. Kidney Int. 2020 May;97(5):829-838.

25. Durvasula R, Wellington T, McNamara E, Watnick S. COVID-19 and kidney failure in the acute care setting: our experience from Seattle. Am J Kidney Dis. 2020 jul;76(1):4-6.

26. Diao B, Wang C, Wang R, Feng Z, Tan Y, Wang H, et al. Human kidney is a target for novel severe acute respiratory syndrome Coronavirus 2 (SARS-CoV-2) infection [Internet]. medRxiv; 2020 Mar. Available from: http://medrxiv.org/lookup/doi/10.1101/2020.03.04.20031120

27. Hirsch JS, Ng JH, Ross DW, Sharma P, Shah HH, Barnett RL, et al. Acute kidney injury in patients hospitalized with COVID-19. Kidney Int. 2020 Jul;98(1):209-218.

28. Huang C, Wang Y, Li X, Ren L, Zhao J, Hu Y, et al. Clinical features of patients infected with 2019 novel Coronavirus in Wuhan, China. Lancet. 2020 Feb 15;395(10223):497-506.

29. Batlle D, Soler MJ, Sparks MA, Hiremath S, South AM, Welling PA, et al. Acute kidney injury in COVID-19: emerging evidence of a distinct pathophysiology. J Am Soc Nephrol. 2020 Jul;31(7):1380-1383.

30. Su H, Yang M, Wan C, Yi L-X, Tang F, Zhu H-Y, et al. Renal histopathological analysis of 26 postmortem findings of patients with COVID-19 in China. Kidney Int. 2020 Jul;98(1):219-227.

31. Lai ASH, Lai KN. Viral nephropathy. Nat Clin Pract Nephrol. 2006 May;2(5):254-262.

32. Kissling S, Rotman S, Gerber C, Halfon M, Lamoth F, Comte D, et al. Collapsing glomerulopathy in a COVID-19 patient. Kidney Int. 2020 Jul;98(1):228-231.

33. Lim J-H, Park S-H, Jeon $\mathrm{Y}$, Cho J-H, Jung H-Y, Choi J-Y, et al. Fatal outcomes of COVID-19 in patients with severe acute kidney injury. J Clin Med. 2020 Jun 3;9(6):1718.

34. Varga Z, Flammer AJ, Steiger P, Haberecker M, Andermatt R, Zinkernagel AS, et al. Endothelial cell infection and endotheliitis in COVID-19. Lancet. 2020 may 2;395(10234):1417-1418.

35. May MT, Gompels M, Delpech V, Porter K, Orkin C, Kegg S, et al. Impact on life expectancy of HIV-1 positive individuals of CD4+ cell count and viral load response to antiretroviral therapy. AIDS. 2014 May 15;28(8):1193-202.

36. Keating SM, Jacobs ES, Norris PJ. Soluble mediators of inflammation in HIV and their implications for therapeutics and vaccine development. Cytokine Growth Factor Rev. 2012 Aug-Oct;23(4-5):193-206.

37. Zapata HJ, Shaw AC. Aging of the human innate immune system in HIV infection. Curr Opin Immunol. 2014 Aug;29:127-136. 
38. Wyatt C. KDIGO webinar on the kidney and HIV: implications for treatment and prevention [Internet]. Yaoundé, Cameroon: KDIGO; 2017 [cited 2020 Jun 19]. Video: 49:04 min. Available from: https://www.youtube. $\mathrm{com} /$ watch?time_continue $=452 \& \mathrm{v}=F h 7 R b c D \times A$ _\&feature=emb_logo

39. Li Y, Shlipak MG, Grunfeld C, Choi Al. Incidence and risk factors for acute kidney injury in HIV infection. Am J Nephrol. 2012;35(4):327-334.

40. Nadkarni GN, Patel AA, Yacoub R, Benjo AM, Konstantinidis I, Annapureddy $\mathrm{N}$, et al. The burden of dialysis-requiring acute kidney injury among hospitalized adults with HIV infection: a nationwide inpatient sample analysis. AIDS. 2015 Jun 1;29(9):1061-1066.

41. Franceschini N, Napravnik S, Eron JJ Jr, Szczech LA, Finn WF. Incidence and etiology of acute renal failure among ambulatory HIV-infected patients. Kidney Int. 2005 Apr;67(4):1526-1531.

42. Wyatt CM, Klotman PE, D'Agati VD. HIV-associated nephropathy: clinical presentation, pathology, and epidemiology in the era of antiretroviral therapy. Semin Nephrol. 2008 Nov;28(6):513-522.

43. Bade NA, Giffi VS, Baer MR, Zimrin AB, Law JY. Thrombotic microangiopathy in the setting of human immunodeficiency virus infection: high incidence of severe thrombocytopenia. J Clin Apher. 2018 Jun;33(3):342-348.

44. Benjamin M, Terrell DR, Vesely SK, Voskuhl GW, Dezube BJ, Kremer Hovinga JA, et al. Frequency and significance of HIV infection among patients diagnosed with thrombotic thrombocytopenic purpura. Clin Infect Dis. 2009 Apr 15;48(8):1129-1137.

45. Novitzky N, Thomson J, Abrahams L, du Toit C, McDonald A. Thrombotic thrombocytopenic purpura in patients with retroviral infection is highly responsive to plasma infusion therapy. Br J Haematol. 2005 Feb;128(3):373379.

46. Gunther K, Garizio D, Nesara P. ADAMTS13 activity and the presence of acquired inhibitors in human immunodeficiency virus-related thrombotic thrombocytopenic purpura. Transfusion. 2007 Sep;47(9):1710-1716.

47. Ucar A, Fernandez HF, Byrnes JJ, Lian EC-Y, Harrington WJ Jr. Thrombotic microangiopathy and retroviral infections: a 13-year experience. Am J Hematol. 1994 Apr;45(4):304-309.

48. Medapalli RK, Parikh CR, Gordon K, Brown ST, Butt AA, Gibert CL, et al. Comorbid diabetes and the risk of progressive chronic kidney disease in HIV-infected adults: data from the veterans aging cohort study. J Acquir Immune Defic Syndr. 2012 Aug 1;60(4):393-399.

49. Mallipattu SK, Liu R, Zhong Y, Chen EY, D'Agati V, Kaufman L, et al. Expression of HIV transgene aggravates kidney injury in diabetic mice. Kidney Intl. 2013 Apr;83(4):626-634.

50. INSIGHT START Study Group. Initiation of antiretroviral therapy in early asymptomatic HIV infection. N Engl J Med. 2015 Aug 27;373(9):795-807.

51. Achhra AC, Mocroft A, Reiss P, Sabin C, Ryom L, de Wit S, et al. Shortterm weight gain after antiretroviral therapy initiation and subsequent risk of cardiovascular disease and diabetes: the D:A:D study. HIV Med. 2016 Apr;17(4):255-268.

52. Achhra AC, Mocroft A, Ross M, Ryom-Nielson L, Avihingsanon A, Bakowska $E$, et al. Impact of early versus deferred antiretroviral therapy on estimated glomerular filtration rate in HIV-positive individuals in the START trial. Int J Antimicrob Agents. 2017 Sep;50(3):453-460.

53. Gupta SK, Anderson AM, Ebrahimi R, Fralich T, Graham H, ScharenGuivel V, et al. Fanconi syndrome accompanied by renal function decline with tenofovir disoproxil fumarate: a prospective, case-control study of predictors and resolution in HIV-infected patients. In: Seguro AC, editor. PLoS One. 2014 Mar 20;9(3):e92717.

54. World Health Organization. [Internet]. 2020 Jul 27 [cited 2021 Feb 25]. Hepatitis B; [about 8p] Available from: https://www.who.int/news-room/ fact-sheets/detail/hepatitis-b

55. Cattran DC, Feehally J, Cook HT, Liu ZH, Fervenza FC, Mezzano SA, et al. Kidney Disease: Improving Global Outcomes (KDIGO) glomerulonephritis work group. KDIGO clinical practice guideline for glomerulonephritis. Kidney Int Suppl. 2012 Jun;2(2):139-274.

56. Chan TM, Lok ASF. Kidney disease associated with hepatitis $B$ virus infection. In: Post TW (ed). UpToDate. Waltham: UpToDate; 2021. Available from: https://www.uptodate.com/contents/kidney-diseaseassociated-with-hepatitis-b-virus-infection. Cited: September 29, 2020.
57. Kupin WL. Viral-associated GN: hepatitis $B$ and other viral infections. Clin J Am Soc Nephrol. 2017 Sep 7;12(9):1529-1533.

58. 58. European Association for the Study of the Liver.. EASL 2017 clinical practice guidelines on the management of hepatitis B virus infection. J Hepatol. 2017 Aug;67(2):370-398.

59. Li P, Wei R-B, Tang L, Wu J, Zhang X-G, Chen X-M. Clinical and pathological analysis of hepatitis $B$ virus-related membranous nephropathy and idiopathic membranous nephropathy. Clin Nephrol. 2012 Dec;78(6):456-464.

60. Xie Q, Li Y, Xue J, Xiong Z, Wang L, Sun Z, et al. Renal phospholipase $A 2$ receptor in hepatitis $B$ virus-associated membranous nephropathy. Am J Nephrol. 2015;41(4-5):345-353.

61. Larsen CP, Messias NC, Silva FG, Messias E, Walker PD. Determination of primary versus secondary membranous glomerulopathy utilizing phospholipase A2 receptor staining in renal biopsies. Mod Pathol. 2013 May;26(5):709-715.

62. Li S-J, Xu S-T, Chen H-P, Zhang M-C, Xu F, Cheng S-Q, et al. Clinical and morphologic spectrum of renal involvement in patients with $\mathrm{HBV}$-associated cryoglobulinaemia. Nephrology (Carlton). 2017 Jun;22(6):449-455.

63. Yang $Y$, Wang $X$, Zhang $Y$, Yuan $W$. Hepatitis $B$ virus $X$ protein and proinflammatory cytokines synergize to enhance TRAIL-induced apoptosis of renal tubular cells by upregulation of DR4. Int J Cell Biol. 2018; Apr97:62-72.

64. Wang X, Zhou Y, Zhu N, Wang L, Gu L-J, Yuan W-J. The deposition of Notch1 in hepatitis B virus-associated nephropathy and its role in hepatitis $B$ virus $X$ protein-induced epithelial-mesenchymal transdifferentiation and immunity disorder in renal tubular epithelial cells. J Viral Hepat. 2014 Oct;21(10):734-743.

65. Sampliner RE. Chronic non-A, non-B liver disease. Need for diagnostic criteria and course definition. Arch Intern Med. 1981 Nov;141(12):15811582.

66. Fabrizi F, Messa P, Martin P. Novel evidence on hepatitis $C$ virus-associated glomerular disease. Kidney Int. 2014 Sep;86(3):466-469.

67. Angeletti A, Cantarelli C, Cravedi P. HCV-Associated nephropathies in the era of direct acting antiviral agents. Front Med (Lausanne). 2019 Feb;6:20.

68. Fabrizi F, Cerutti R, Porata G, Messa P, Ridruejo E. Direct-acting antiviral agents for HCV-associated glomerular disease and the current evidence. Pathogens. 2019 Oct 4;8(4):176.

69. Duffell EF, Hedrich D, Mardh O, Mozalevskis A. Towards elimination of hepatitis $B$ and $C$ in European Union and European Economic Area countries: monitoring the World Health Organization's global health sector strategy core indicators and scaling up key interventions. Euro Surveill. 2017 Mar 2;22(9):30476.

70. Negro F, Forton D, Craxì A, Sulkowski MS, Feld JJ, Manns MP. Extrahepatic morbidity and mortality of chronic hepatitis C. Gastroenterology. 2015 Nov;149(6):1345-1360.

71. Cacoub P, Gragnani L, Comarmond C, Zignego AL. Extrahepatic manifestations of chronic hepatitis C virus infection. Dig Liver Dis. 2014 Dec;46 Suppl 5:S165-173.

72. Kidney Disease: Improving Global Outcomes (KDIGO) Hepatitis CWork Group. KDIGO 2018 Clinical Practice Guideline for the prevention, diagnosis, evaluation, and treatment of hepatitis $C$ in chronic kidney disease. Kidney Int Suppl. 2018 Oct;8(3):91-165.

73. McGuire BM, Julian BA, Bynon JS Jr, Cook WJ, King SJ, Curtis JJ, et al. Brief communication: glomerulonephritis in patients with hepatitis C cirrhosis undergoing liver transplantation. Ann Intern Med. 2006 May;144(10):735-741.

74. Gupta A, Quigg RJ. Glomerular diseases associated with hepatitis B and C. Adv Chronic Kidney Dis. 2015 Sep;22(5):343-351.

75. Noble J, Jouve T, Malvezzi P, Rostaing L. Renal complications of liver diseases. Expert Rev Gastroenterol Hepatol. 2018 Nov;12:1135-1142.

76. De Re V, Sansonno D, Simula MP, Caggiari L, Gasparotto D, Fabris M, et al. HCV-NS3 and IgG-Fc crossreactive IgM in patients with type II mixed cryoglobulinemia and B-cell clonal proliferations. Leukemia. 2006 Jun;20(6):1145-1154.

77. Lunel F, Musset L, Cacoub P, Frangeul L, Cresta P, Perrin M, et al. Cryoglobulinemia in chronic liver diseases: role of hepatitis $C$ virus and liver damage. Gastroenterology. 1994 May;106(5):1291-300. 
78. Adinolfi LE, Utili R, Attanasio V, Zampino R, Ragone E, Tripodi MF, et al. Epidemiology, clinical spectrum and prognostic value of mixed cryoglobulinaemia in hepatitis $C$ virus patients: a prospective study. Ital J Gastroenterol. 1996 Jan;28(1):1-9.

79. Sene D, Limal N, Ghillani-Dalbin P, Saadoun D, Piette J-C, Cacoub P. Hepatitis $C$ virus-associated B-cell proliferation--the role of serum B lymphocyte stimulator (BLyS/BAFF). Rheumatology (Oxford). 2007 Jan;46(1):65-9.
80. Fabris M, Quartuccio L, Sacco S, De Marchi G, Pozzato G, Mazzaro C, et al. B-Lymphocyte stimulator (BLyS) up-regulation in mixed cryoglobulinaemia syndrome and hepatitis- $C$ virus infection. Rheumatology (Oxford). 2007 Jan;46(1):37-43.

81. De Vita S, Quartuccio L, Isola M, Mazzaro C, Scaini P, Lenzi M, et al. A randomized controlled trial of rituximab for the treatment of severe cryoglobulinemic vasculitis. Arthritis Rheum. 2012 Mar;64(3):843-853. 